Lehto L, Rantala L, Vilkman E, Alku P, Bäckström T, Experiences of a short vocal training course for call-centre customer service advisors, Folia Phoniatrica et Logopaedica, 2003; 55: 163-176.

(C) 2003 S. Karger AG

Reprinted with permission.

This article is copyright protected. Any distribution without written consent from S. Karger AG, Basel is a violation of the copyright. 


\section{Experiences of a Short Vocal Training Course for Call-Centre Customer Service Advisors}

\author{
Laura Lehto $^{a, b}$ Leena Rantala $^{c}$ Erkki Vilkman ${ }^{a, d}$ Paavo Alku ${ }^{b}$ \\ Tom Bäckström ${ }^{b}$ \\ aPhoniatric Department, ENT Clinic, Helsinki University Central Hospital and 'baboratory of \\ Acoustics and Audio Signal Processing, Helsinki University of Technology, Helsinki, and \\ 'Clinical Neurophysiology, Cognitive Laboratory, Oulu University Central Hospital and \\ dPhoniatric Department, ENT Clinic, University of Oulu, Oulu, Finland
}

(C) Free Author Copy - for personal use only ANY DISTRIBUTION OF THIS ARTICLE WITHOUT WRITTEN CONSENT FROM S. KARGER AG, BASEL IS A VIOLATION OF THE COPYRIGHT.

Written permission to distribute the PDF will be granted against payment of a permission fee, which is based on the number of accesses required. Please contact permission@karger.ch

\section{Key Words}

Voice training . Speech professionals . Occupational voice $\cdot$ Vocal loading

\begin{abstract}
It is commonly known that occupational voice users suffer from voice symptoms to varying extents. The purpose of this study was to find out the effects of a short (2-day) vocal training course on professional speakers' voice. The subjects were 38 female and 10 male customer advisors, who mainly use the telephone during their working hours at a call centre. The findings showed that although the subjects did not suffer from severe voice problems, they reported that the short vocal training course had an effect of some of the vocal symptoms they had experienced. More than $50 \%$ of the females and males reported a decrease in the feeling of
\end{abstract}

\begin{tabular}{ll}
\hline KARGER & ( ) 2003 S. Karger AG, Basel \\
1021-7762/03/0554-0163\$19.50/0 \\
$\begin{array}{l}\text { Fax + 41 61306 1234 } 34 \text { kail ker@karger.ch } \\
\text { www.karger.com }\end{array}$ & $\begin{array}{l}\text { Accessible online at: } \\
\text { www.karger.com/fpl }\end{array}$
\end{tabular}

mucus and the consequent need to clear the throat, and diminished worsening of their voice. Over $60 \%$ thought that voice training had improved their vocal habits and none reported a negative influence of the course on their voice. Females also reported a reduction of vocal fatigue. The subjects were further asked to respond to 23 statements on how they experienced the voice training in general. The statements 'l learned things that I didn't know about the use of voice in general' and 'I got useful and important knowledge concerning my work' were highly assessed by both females and males. The results suggest that even a short vocal training course might affect positively the self-reported wellbeing of persons working in a vocally loading occupation. However, to find out the longterm effects of a short training course, a follow-up study would need to be carried out.

Copyright $@ 2003$ S. Karger AG, Basel

Laura Lehto

Laboratory of Acoustics and Audio Signal Processing

Helsinki University of Technology, PO Box 3000

FIN-02015 Helsinki (Finland)

Tel. +358 50583 9973, Fax + 3589460 224, E-Mail laura.lehto@iki.fi 


\section{Introduction}

Professional voice users can be defined as: (a) those who depend on a consistent, special, or appealing voice quality as a primary tool of trade and (b) those who, if afflicted with dysphonia or aphonia, would generally be discouraged in their jobs and would seek alternative employment [ref. 1, p. 254]. In the US, it is estimated that 28 million people (approximately $25 \%$ of the labour force) work in professions which place demands on the voice [2]. In Finland, where the present study took place, altogether 700,000 employees, or approximately $30 \%$ of the Finnish labour force, hold such jobs [3]. Furthermore, it has been argued that voice use in various professional and social contexts is constantly growing [4], due to the prevalence of new speech technology applications, such as mobile phones.

Most studies of the professional use of the voice have focused on the occupational problems of teachers' voices [1, 5-14]. This is understandable, because teachers constitute one of the largest professional groups depending on their voice [3]. Furthermore, teachers, in particular, make up an occupational group in which extensive long-term vocal loading is combined with a need for a high-quality voice. However, according to a study by Morton and Watson [15], many teachers regard their vocal symptoms as inherent to their occupation and do not necessarily take appropriate countermeasures. Hence, preventive voice care needs to be emphasised as a tool to sustain occupational capacity.

An occupational disease can be defined as a disease most likely to be caused by exposure at work. People who use their voice professionally are at risk for occupational voice disorders. Voice disorders may involve abnormality of the larynx, which causes the laryngeal mechanism to fail to meet the functional voicing needs of the speaker. Voice disorders often cause an audible deviation in voice quality [16], and they may affect both daily activities and social functioning [17]. The inability to produce normal voice may be associated with stress, frustration, withdrawal and depression [18]. Proper treatment of voice problems plays a key role in restoring and preserving the individual's occupational capacity and, consequently, his or her economic situation as well as quality of life [19]. Early identification and treatment of a voice problem is likely to reduce its severity and the time needed for recovery [11].

The risk factors for voice professionals include background noise, poor room acoustics, long speaking distance, poor quality of air (dryness, dust), poor working posture and vocal loading per se by speaking or singing [20]. The occupational safety and health arrangements of voice and speech professionals are, however, poorly developed compared to many other professions. For example, repetition strain injuries are considered occupational diseases, whereas occupational vocal nodules, which can often be seen as a consequence of repeated movements of vocal folds, are not generally accepted in this category [21].

Moreover, according to the European occupational safety and health legislation, 'the employer is obliged to take care of the prevention of occupational risks, the protection of safety and health, the elimination of risks and accident factors, the informing, consultation ... and training ..., as well as general guidelines for the implementation of the said principles' [22]. To meet this challenge, professional voice users should be provided with basic knowledge of vocal care.

\section{Goal of the Study}

This project was initiated by the largest Finnish telecommunications operator Sonera in an effort to gather data about the voices of their call-centre personnel. Telephone mar- $\overline{164} \quad \overline{\text { Folia Phoniatr Logop 2003;55:163-176 }}$
Lehto/Rantala/Vilkman/Alku/ Bäckström 
Table 1. Description of the background variables of the subjects

\begin{tabular}{|c|c|c|c|c|c|c|c|}
\hline & \multirow[t]{2}{*}{$\mathrm{n}$} & \multicolumn{2}{|l|}{ Age } & \multicolumn{2}{|c|}{ Working experience } & \multicolumn{2}{|c|}{ Smoking } \\
\hline & & mean & range & mean & range & no & yes \\
\hline Females & 38 & 29 & $21-40$ & 15 months & 1 month-10 years & $61 \%$ & $39 \%$ \\
\hline Males & 10 & 26 & $21-38$ & 7 months & 2 months- 1 year & $70 \%$ & $30 \%$ \\
\hline
\end{tabular}

keters constitute an interesting subgroup of salespersons because their working ability depends exclusively on their voice. On the telephone, the speaker must rely merely on his/ her voice, without getting support from body language or written communication. At Sonera, it had been noted that the call-centre personnel had more sick-leave than the other groups of employees and the company therefore wished to analyse the reasons for this. The objective was to improve the working environment of the help-desk personnel and to cut down the incidence of voice failures leading to sick-leave.

The specific goals of this study were to find out (1) how often telephone workers experience vocal symptoms; (2) how a short vocal training course affects the subjective vocal symptoms; (3) the relationship between the change in voice symptoms and the subjective effect of vocal training, and finally (4) how vocal training is experienced in general.

\section{Materials and Methods}

\section{Subjects}

The subjects were 38 female and 10 male customer advisors, who mainly use the telephone during their working hours at a call-centre. They work partly in three shifts: morning shift starts at 7.00-8.30 a.m., day shift at 9.00-10.30 a.m. and night shift at 12.30 $4.30 \mathrm{p} . \mathrm{m}$. The length of the working day is $8 \mathrm{~h}$, including a 29-min lunch break and two 10-min coffee breaks. The description of the subjects is shown in table 1.

Experiences of a Short Vocal Training Course
The subjects were asked about certain background factors that might have an effect on their voice. The questions concerned their hobbies (whether they included intense voice use, such as singing, acting, cheering at sport, etc.) and elicited whether they had allergic rhinitis or asthma, any chronic diseases or regular medication, especially asthma medication or hormonal preparations. The subjects were also asked if they had colds very often (more than 4 times a year), how much alcohol they consumed, whether they had a hearing loss or gastro-oesophageal reflux disease, and whether they had sought professional help for voice problems in the past. The subjects were also examined by a phoniatrician. A phoniatric examination includes, for instance, perceptual voice analysis and laryngeal examination with a mirror.

\section{Working Environment}

The subjects worked in an open-plan office, where individual working spaces are separated by movable partition walls. According to a work hygiene survey conducted by the Oulu Regional Institute of Occupational Health, the background noise level in the office is $42 \mathrm{~dB}(\mathrm{~A})$, which can be considered low. The room temperature was quite high $\left(23^{\circ} \mathrm{C}\right)$, which caused the air to be relatively dry; ambient humidity was only $19 \%$ instead of the recommended $25-45 \%$. Formaldehyde concentration $(0.1-0.2 \mathrm{ppm})$ also exceeded the recommendations $(<0.03 \mathrm{ppm})$. A probable reason for this could be the recent renovation of the office as new furniture often contains formaldehyde. A series of studies have indicated that drying negatively affects certain aspects of vocal performance [23-26], and even a low concentration of formaldehyde is known to affect the mucous membrane of the respiratory tract [e.g. ref. 27].

Considering voice use, two harmful working postures are common. One is the position where the upper part of the back bends down while the shoulders are pushed forwards. In the other, the head leans forward, which causes tension in the neck and throat. In order to 
alleviate these problems, both the working postures and the work stations of the subjects were examined by the Oulu Regional Institute of Occupational Health. The subjects were given information about how to correct the inappropriate working postures by adjusting their work stations. However, each work station had several users during the week and individual adjustments were therefore seldom made.

\section{Short-Term Voice Training Course}

The subjects were given vocal training for 2 days by a speech-language therapist. The training program comprised both indirect and direct therapy methods [e.g. ref. 28].

The first day consisted of $6 \mathrm{~h}$ divided into two sections. The first section consisted of lectures on the theory of voice production, resonance and articulation. The basics of vocal hygiene, balanced breathing patterns and the importance of good body posture were also discussed as tools to reduce tension when speaking. The subjects were also provided with information about the kinds of foods and drinks that may have a negative effect on their voice. The second part of the day included vocal activities. The subjects were taught different vocal exercises: they were informed of how to use their voice more economically and they learned exercises to warm up or cool down their voice. The exercises that were used are widely recognised and clinically used. The whole second day of the training course was spent practising these vocal exercises.

After the 2-day vocal health programme, the subjects participated in a speech communication seminar for 1 day. The following topics were discussed: principles of speech technique, the special demands of telephone communication, the mental impressions transmitted by voice and goal-oriented and well-focused communication. The speech communication seminar was given by a speech teacher.

\section{Data Collection}

Before the voice training course, the subjects filled in a questionnaire on how often they experienced certain subjective voice problems. In this context the word 'subjective' refers to the subjects' own judgement about how accurate the definition of the symptom is. Hereafter the term 'symptom' will be used to refer to these self-reported symptoms.

The questionnaire included eleven different symptoms (the terms given in parentheses are used in the result tables and appendices):

(1) My voice gets tired very easily (Fatigue).

(2) My voice is hoarse even when I don't have a flu (Hoarse).
(3) I have a feeling of a lump in my throat (Lump).

(4) I feel like having a choker around my neck (Choker).

(5) I have a feeling of mucus in my throat and/or I need to clear my throat frequently (Mucus).

(6) My throat is dry and/or itchy (Dry).

(7) In noisy circumstances my voice might not be heard (Not heard).

(8) My voice gets worse during the day (Worse).

(9) My voice breaks when I speak (Breaks).

(10) I have lost my voice totally even when I haven't had a flu (No-flu lost).

(11) I have been absent from work because of my voice (Sick-leave)

The subjects used a four-item scale (numbered from 1 to 4) to estimate how often they have had these symptoms. On this scale, 1 referred to symptoms 'not even once a year or never', 2 'a few times a year or sometimes', 3 'approximately once a month or quite often' and 4 'almost every week of very often'.

Three weeks after the voice training course, the subjects filled in an additional questionnaire to describe the effects of the training on the symptoms addressed in the first questionnaire. The second questionnaire also contained a new question, 'My voice has changed due to the voice training' (question 12). This time the scale was from -5 to 5 , where -5 signified a considerable change towards worse, zero meant no change and 5 meant the maximum change towards better. There was also the alternative 'As I didn't experience this symptom before the training, I cannot notice a difference'.

The subjects were also asked how they experienced the voice training in general. This questionnaire was filled in simultaneously with the one mentioned above. Such statements as 'I learned something that I didn't know about voice production' and 'While speaking, I learned to control my speaking body posture and positions better than before' were present. The questionnaire included altogether 23 different statements, which are present in Appendix C. The scale of assessments was from 0 (not at all) to 5 (very much). All the questionnaires were filled in during the morning shift.

\section{Data Analysis}

All the symptoms will be discussed when reporting the responses to the question regarding both the frequency of voice symptoms and the change in the symptoms after the training course. However, when discussing the relationship between the change in the symptoms and the subjective effect of the training, we will focus only on the symptoms known to be most com-
166

Folia Phoniatr Logop 2003;55:163-176
Lehto/Rantala/Vilkman/Alku/ Bäckström 
mon among professional voice users. On the basis of the literature on the hazards experienced by voice workers, we chose the following three symptoms to represent vocal working ability (or its impairment): voice fatigue, hoarseness and worsening of voice quality $[7,14,29-31]$. Additionally, we investigated the correlation between the subjective change in the overall voice quality due to the training and the experiences of training.

The results obtained are presented as means, standard deviations (SD) and ranges. ANOVA's and Spearman's correlation were computed with the Statistical Package for the Social Sciences software (SPSS 10.0 for Windows).

\section{Results}

\section{Frequency of Voice Symptoms}

The reported voice symptoms and their frequency before the training programme are shown in Appendix A for both females and males. The most common symptom for females was the feeling of mucus in the throat and the consequent need to clear the throat. This kind of sensation was reported to occur almost 'once a month or quite often'. Taken together, females did not experience voice problems 'very often'. The problems that were experienced 'a few times a year or sometimes' were hoarseness without a cold, vocal fatigue after extensive speaking, a sensation of a dry throat, worsening of voice quality during the day and a feeling of a lump in the throat.

Among males, too, the most common symptom was the need to clear the throat, which they experienced 'once a month or quite often'. The second most common symptoms were voice fatigue and the sensation of a dry throat. These two symptoms were experienced by males ' a few times a year or sometimes'.

Statistical analyses showed that females had more vocal hoarseness without a flu (question 2) than males [ANOVA, F $(1,47)=$ $5.060 ; \mathrm{p}=0.029$ ] and that their voice got worse during the day (question 8) more often than that of males [ANOVA, $\mathrm{F}(1,47)=6.338$; $\mathrm{p}=0.015]$.

The assessments of the symptoms were pooled together for each subject. Below, this score will be referred to as the symptom score (maximum 44). The larger the number of symptoms and the higher their frequency, the higher is this symptom score. Therefore, the symptom score reflects the severity of the voice problems of each subject. The mean symptom score for females was 16.3 (SD 7.7, range 2-33) and for males 12.4 (SD 4.7, range 6-21). There was no significant difference between the genders [ANOVA: $F(1,47)=0.178, \mathrm{NS})$.

\section{Background Factors and Their Relation with the Experienced Symptoms}

The most common potentially relevant background factor for women was the use of a hormonal preparation (47\%). The other common background factors were smoking (39\%), allergy or asthma (29\%), gastro-oesophageal reflux disease (18\%) and frequent colds (16\%). Hobbies that require heavy voice use were reported by $13 \%$ of the women. Four subjects $(10 \%)$ had sought professional help for their voice problems. Voice disorders had been diagnosed in 2 subjects, and 1 had received voice therapy.

In the phoniatric examination, the most common finding for female subjects was incomplete interarytenoid closure of the vocal folds, that was seen in 13 subjects. This is the most prevalent closure pattern during phonation for females with normal speech [32-34] and can be considered to be typical of female vocal folds and within normal variance [35]. Two women also had oedema (both smokers) and 5 had erythema of vocal folds (all smokers).

In males, smoking was the most common background factor (30\%). Hobbies that require intense voice use, allergy and gastro- 
oesophageal reflux disease were mentioned by $20 \%$ (2 subjects) each. One subject reported poor hearing, and 1 had asthma. Incomplete closure of vocal folds was found in 1 subject. $\mathrm{He}$ also had both erythema and oedema of vocal folds. One subject has oedema and 2 had erythema. All these findings were recorded in smokers.

When analysing the relationships between the most common background variables and the self-reported voice symptoms, only a few statistically significant linkages were found. Allergic rhinitis or asthma was connected with hoarseness without a flu [ANOVA, F(3, $37)=4.180 ; \mathrm{p}=0.013]$ and with the symptom score [ANOVA, $F(2,37)=4.127 ; p=0.025$ ]. Hobbies that require heavy voice use affected the feeling of 'choker around the neck' [ANOVA, $F(2,37)=4.320 ; p=0.021$ ]. In males, the only significant link was between smoking and the feeling of mucus in the throat [ANOVA, $F(2,9)=6.300 ; p=0.027$ ]

\section{Change in Vocal Symptoms after Training}

It appeared that, for females, three of the eleven symptoms reported at the baseline were most affected by the voice training. The effect of the training or vocal symptoms is shown in Appendix B both for females and for males. As a result of the training, the females reported diminished vocal fatigue (60.5\%), a diminished feeling of mucus and need to clear the throat (50\%) and a diminished worsening of the voice $(65.5 \%)$. On the whole, $63 \%$ of the females said that the voice training had improved their vocal habits and none of them reported a negative influence on their voice.

Those symptoms that diminished in females also decreased in males; the feeling of mucus and need to clear the throat $(50 \%)$ and the worsening of the voice $(50 \%)$. Among males, $60 \%$ experienced improved vocal habits due to the training, and none reported a negative influence on his voice.

\section{Subjects' Evaluation of Voice Training}

As can be seen in Appendix C, the subjects experienced the voice training very positively. Females gave the highest score to the statement 'I got useful and important knowledge concerning my work' (No. 19). Furthermore, the statements 'I learned things that I didn't know about the use of voice in general' (No. 13) and 'I learned to control my speaking body posture and positions better than before' (No. 16) were highly assessed by female respondents. Males also gave favourable responses to the questions concerning the training. The most approving responses were given to 'I learned things that I didn't know about the use of voice in general' and 'I got useful and important knowledge concerning my work'.

The length of the training and its content were considered adequate by $63 \%$ of the female employees, while $34 \%$ of them thought that the training could have been different in some way. These answers included the following opinions: 'Training could have lasted longer', 'There should have been more time for practising', 'One more day would be useful', 'More personal guidance'. More training was looked forward to by $76 \%$ of the female participants. A possibility to attend an advanced course was considered necessary in $5 \%$ of the answers. None of the respondents thought that more training would not be useful.

Of males, $67 \%$ were quite satisfied with the contents and length of the training. One person thought that the other day was unnecessary. The following statements were also given: 'Slightly too short compared to the amount of new knowledge', 'A lot of new information in short time'. The males showed less interest in taking an advanced training course.
Lehto/Rantala/Vilkman/Alku/ Bäckström 
Relationship between the Change in Voice Symptoms and the Experienced Effect of the Training

The statistically significant correlation between the change in the three chosen voice symptoms and the experienced effect of the training as reported by females and males are given in the tables 2 and 3, respectively. For females, there were two statements that seemed to have a significant correlation with all the chosen symptoms: 'My voice production has become easier after the training' (No. 3) and 'I can now use my voice as a tool of communication more effectively than before' (No. 22).

The statements (Better understanding of voice production helps to take care of my voice' (No. 4) and 'Knowledge of the factors affecting my voice helps to take better care of my voice' (No. 6) had a connection with three of the four symptoms: statement 4 with diminished fatigue, diminished hoarseness and diminished voice worsening, and statement 6 with diminished fatigue, diminished hoarseness and overall quality change.

Furthermore, statement 19, 'I got useful and important knowledge concerning my work', had a significant correlation with diminished hoarseness and with the change in overall voice quality. Statement 23, 'I can now react to the client's speaking pattern better than before', correlated significantly with diminished fatigue and with the change in overall voice quality. For the other statements, the statistically significant correlations were sparse.

Males gave no preference to any specific statement. It is noteworthy that there were only 10 males, which is why the individual opinions vary greatly and the result is no more than suggestive. However, the change in overall voice quality and statement 3 , 'My voice production has become easier after the training', showed a correlation.

Experiences of a Short Vocal Training Course

\section{Discussion}

The definition of a voice problem is not at all straightforward. A voice problem is a multidimensional phenomenon that usually includes a self-perceived reduction in physical, social, emotional and/or professional wellbeing. It can be seen as a complex of selfreported symptoms and clinically observed signs [2]. This definition is in line with ICIDH-2, the new version of the International Classification of Impairments, Disabilities and Handicaps, proposed by the World Health Organization [36]. If a person reports sufficient concerns and functional disruption in his/her voice, nobody can rebut them.

Most studies on the effects of voice training have focused on therapy programmes lasting for months with weekly sessions [37, 38]. Previously, the effects of a short vocal hygiene course were studied by Broaddus-Lawrence et al. [39], but their subjects were all singers. To the best of our knowledge, the present study is the first to investigate the effects of a short course arranged for healthy professional speakers, who are 'ordinary' employees in the sense that they are not trained singers or actors. Moreover, the emphasis in the current study was on the effects of preventive voice care.

The first goal of this study was to find out how often telephone workers experience vocal symptoms. The most frequently occurring symptom was the sensation of mucus in the throat and consequent need to clear the throat. The second most common symptom, the sensation of a dry throat, may be related to the relatively low ambient humidity in the office. The other commonly experienced symptoms were voice fatigue and hoarseness without a cold. Interestingly, the three lastmentioned symptoms were exactly the same as those reported to be most common among teachers at day care centres in a recent study

Folia Phoniatr Logop 2003;55:163-176 
Table 2. Relationship between the change in voice symptoms and the experienced effect of training in female subjects

\begin{tabular}{|c|c|c|c|}
\hline Change in voice fatigue & $\mathrm{n}=28$ & $\begin{array}{l}\mathrm{q} 3 \\
\mathrm{q} 4 \\
\mathrm{q} 6 \\
\mathrm{q} 18 \\
\mathrm{q} 21\end{array}$ & $\begin{array}{l}\text { My voice production has become easier after the training }\left(\mathrm{r}=0.375 ; \mathrm{p}=0.049^{*}\right) \\
\text { Better understanding of voice production helps me to take care of my voice } \\
\left(\mathrm{r}=0.430 ; \mathrm{p}=0.022^{*}\right) \\
\text { Knowledge of factors affecting my voice helps me to take better care of my voice } \\
\left(\mathrm{r}=0.435 ; \mathrm{p}=0.021^{*}\right) \\
\text { I think that although I got plenty of new knowledge, I still cannot control my voice } \\
\left(\mathrm{r}=0.476 ; \mathrm{p}=0.010^{*} ; \text { reverse coding) }\right. \\
\mathrm{I} \text { can now convey the impression I want when discussing on the phone } \\
\left(\mathrm{r}=0.419 ; \mathrm{p}=0.027^{*}\right) \\
\mathrm{I} \text { can now use my voice as a tool of communication more effectively than before } \\
\left(\mathrm{r}=0.571 ; \mathrm{p}=0.002^{*}\right) \\
\text { I can now react to the client's speaking pattern better than before } \\
\left(\mathrm{r}=0.391 ; \mathrm{p}=0.039^{*}\right)\end{array}$ \\
\hline Change in hoarseness & $\mathrm{n}=23$ & $\begin{array}{l}\text { q3 } \\
\text { q4 } \\
\text { q6 } \\
\text { q11 } \\
\text { q13 } \\
\text { q19 } \\
\text { q22 }\end{array}$ & $\begin{array}{l}\text { My voice production has become easier after the training }\left(\mathrm{r}=0.443 ; \mathrm{p}=0.034^{*}\right) \\
\text { Better understanding of voice production helps me to take care of my voice } \\
\left(\mathrm{r}=0.571 ; \mathrm{p}=0.004^{* *}\right) \\
\text { Knowledge of factors affecting my voice helps me to take better care of my voice } \\
\left(\mathrm{r}=0.597 ; \mathrm{p}=0.003^{* *}\right) \\
\text { Concentration on articulation helps me to keep my voice and speech clear } \\
\left(\mathrm{r}=0.541 ; \mathrm{p}=0.008^{* *}\right) \\
\text { I learned things that } \mathrm{I} \text { didn't know about the use of voice in general } \\
\left(\mathrm{r}=0.447 ; \mathrm{p}=0.032^{*}\right) \\
\text { I got useful and important knowledge concerning my work }\left(\mathrm{r}=0.500 ; \mathrm{p}=0.015^{*}\right) \\
\text { I can now use my voice as a tool of communication more effectively than before } \\
\left(\mathrm{r}=0.549 ; \mathrm{p}=0.008^{* *}\right)\end{array}$ \\
\hline $\begin{array}{l}\text { Change in voice } \\
\text { worsening }\end{array}$ & $\mathrm{n}=29$ & $\begin{array}{l}\text { q3 } \\
\text { q4 } \\
\text { q22 }\end{array}$ & $\begin{array}{l}\text { My voice production has become easier after the training }\left(\mathrm{r}=0.377 ; \mathrm{p}=0.044^{*}\right) \\
\text { Better understanding of voice production helps me to take care of my voice } \\
\left(\mathrm{r}=0.555 ; \mathrm{p}=0.002^{* *}\right) \\
\text { I can now use my voice as a tool of communication more effectively than before } \\
\left(\mathrm{r}=0.555 ; \mathrm{p}=0.002^{* *}\right)\end{array}$ \\
\hline $\begin{array}{l}\text { Change in the overall } \\
\text { voice quality }\end{array}$ & $\mathrm{n}=37$ & $\begin{array}{l}\text { q3 } \\
\text { q5 } \\
\text { q6 } \\
\text { q14 } \\
\text { q15 } \\
\text { q16 }\end{array}$ & $\begin{array}{l}\text { My voice production has become easier after the training }\left(\mathrm{r}=0.386 ; \mathrm{p}=0.018^{*}\right) \\
\text { Voice exercises are easy to do }\left(\mathrm{r}=0.404 ; \mathrm{p}=0.013^{*}\right) \\
\text { Knowledge of factors affecting my voice helps to take better care of my voice } \\
\left(\mathrm{r}=0.442 ; \mathrm{p}=0.006^{* *}\right) \\
\text { While speaking, I succeed to control my breathing better than before } \\
\left(\mathrm{r}=0.353 ; \mathrm{p}=0.032^{*}\right) \\
\text { While speaking, I succeed to control the ease of my voice production better than } \\
\text { before }\left(\mathrm{r}=0.552 ; \mathrm{p}=0.000^{* *}\right) \\
\text { While speaking, I learned to control my speaking body posture and positions } \\
\text { better than before }\left(\mathrm{r}=0.530 ; \mathrm{p}=0.001^{* *}\right) \\
\text { I got useful and important knowledge concerning my work }\left(\mathrm{r}=0.349 ; \mathrm{p}=0.034^{*}\right) \\
\text { I can now use my voice as a tool of communication more effectively than before } \\
\left(\mathrm{r}=0.381 ; \mathrm{p}=0.022^{*}\right) \\
\text { I can now react to the client's speaking pattern better than before } \\
\left(\mathrm{r}=0.389 ; \mathrm{p}=0.019^{*}\right)\end{array}$ \\
\hline
\end{tabular}

There is a different $\mathrm{n}$ in different questions because some employees did not experience certain symptoms before the training and it was hence not possible for them to measure how the symptoms would have changed due to the training. 
by Sala et al. [14]. The present respondents did not experience problems 'very often', but 'quite often' or 'sometimes'. Based on the symptom score, females experience problems more often than males, although there was no statistically significant difference. There was also a wider standard deviation among females, which suggests that there is marked interpersonal variation.

Background variables do not seem to have a specific influence on subjective voice problems. Chronic rhinitis or asthma correlated significantly with hoarseness without a flu and a high symptom score. This is understandable in view of the various symptoms caused by chronic rhinitis or asthma. However, it is interesting that hobbies involving heavy voice use only had a significant correlation with the sensation of a 'choker around the neck'. It could have been presumed that voice hobbies would have correlated with voice fatigue or hoarseness, although some studies have reported that there is no connection between voice hobbies and voice problems [40]. Also, the findings of the phoniatric examination supported the conclusion that the vocal loading on the subjects was not heavy enough to cause organic changes, at least during the relatively short time they had spent in their current occupation. For example, there were no instances of diagnosed laryngitis, which is considered the most common organic finding associated with vocal loading [14]. A relatively common finding in the laryngological examination of females was incomplete interarytenoid closure, but it can be considered to be typical of female vocal folds and within normal variance [32-35]. In males, the only correlation was found between smoking and the feeling of mucus in the throat.

Although the present subjects did no suffer from severe voice problems, they reported that the short vocal training course had an effect on some of the vocal symptoms they had experienced. More than $50 \%$ of females and males reported a diminished sensation of mucus and consequent need to clear the throat as well as worsening of their voice. Over $60 \%$ thought that the voice training had improved their vocal habits and nobody reported the course to have exercised a negative influence on their voice. Females also reported that vocal fatigue had diminished.

For females, there seemed to be a clear connection between the change in voice symptoms (Appendix B) and the statements presented about vocal training (Appendix C). There were six statements that correlated with at least two of the following diminished symptoms: vocal fatigue, hoarseness, voice worsening and change in overall voice quality. These statements were: 'My voice production has become easier after the training', 'I can now use my voice as a tool of communication more effectively than before', 'Better understanding of voice production helps to take care of my voice', 'Knowledge of the factors affecting my voice helps to take better care of my voice', 'I got useful and important knowledge concerning my work', and 'I can now react to the client's speaking pattern better than before'.

Males showed no specific trend in the importance of the statements presented, but the statement 'My voice production has become easier after the training' correlated with overall voice quality change. On the contrary, the change in hoarseness correlated negatively with all the three statements (table 3). Considering the small number of males in the present study, we would not like to draw any specific conclusions based on this finding. However, it is possible that this different behaviour of females and males reflects the findings reported by Herrington-Hall et al. [41], according to which women in general appear to be more interested in health, more likely to rec- 
Table 3. Relationship between the change in voice symptoms and the experienced effect of training in male subjects

\begin{tabular}{|c|c|c|c|}
\hline Change in voice fatigue & $\mathrm{n}=5$ & q13 & $\begin{array}{l}\text { I learned things that I didn't know about the use of voice in general } \\
\left(\mathrm{r}=0.889 ; \mathrm{p}=0.044^{*}\right)\end{array}$ \\
\hline \multirow[t]{3}{*}{ Change in hoarseness } & \multirow[t]{3}{*}{$\mathrm{n}=3$} & q6 & $\begin{array}{l}\text { Knowledge of factors affecting my voice helps me to take better care of my voice } \\
\left(\mathrm{r}=-1.00 ; \mathrm{p}=0.000^{* *}\right)\end{array}$ \\
\hline & & $\mathrm{q} 22$ & $\begin{array}{l}\text { I can now use my voice as a tool of communication more effectively than before } \\
\left(\mathrm{r}=-1.00 ; \mathrm{p}=0.000^{* *}\right)\end{array}$ \\
\hline & & $\mathrm{q} 23$ & $\begin{array}{l}\text { I can now react to the client's speaking pattern better than before } \\
\left(\mathrm{r}=-1.00 ; \mathrm{p}=0.000^{* *}\right)\end{array}$ \\
\hline Change in voice worsening & $\mathrm{n}=5$ & q5 & Voice exercises are easy to do $\left(r=0.884 ; p=0.047^{*}\right)$ \\
\hline \multirow[t]{3}{*}{ Change in the overall voice } & \multirow[t]{3}{*}{$\mathrm{n}=9$} & q3 & My voice production has become easier after the training $\left(r=0.707 ; p=0.033^{*}\right)$ \\
\hline & & q7 & Vocal practice helps me to take better care of my voice $\left(r=0.707 ; p=0.033^{*}\right)$ \\
\hline & & $\mathrm{q} 20$ & I think my mood can be inferred from my voice $\left(r=0.718 ; p=0.029^{*}\right)$ \\
\hline
\end{tabular}

There is a different $\mathrm{n}$ in different questions because some employees did not experience certain symptoms before the training and it was hence not possible for them to measure how the symptom would have changed due to the training.

ognise bodily changes as symptoms of illness, and more willing to seek medical care than males. The indication might be that when females get a 'permission' to feel some symptoms and are taught to learn to control these symptoms in some way, they experience it as positive feedback about their self-control. However, when males learn to observe their voice more carefully, it is not always a relief [15]. Because females tend to have more voice problems in general [16], the conclusion is logical: 'patients who seek treatment and perceive themselves to have a great problem appear generally more motivated to make changes than those who do not see much problem with their voice [17, p. 521].

All in all, the subjects' general opinion about the vocal training course was very positive. Both females and males reported that they had got useful and important knowledge that could be applied to their work, and that they had gained new knowledge about voice production. This finding is in line with the results of a similar vocal hygiene short course arranged for untrained singers [39], where the subjects reported a high degree of benefit and learning, although there was a minimal change in vocal hygiene behaviour and perceptual voice characteristics.

In the present study, we chose not to have a control group, because the purpose was to investigate the effects of vocal training in a given group of subjects. The presence/absence of a control group continues to be a target of intensive debate. For example, in a recent article by Carding and Hillman [42], the importance of randomised controlled studies is in focus. However, various studies involving control groups have shown that the group receiving therapy always achieves the best results [14, 34, 43-47].

When we discuss the efficacy of treatment, there are several questions to be considered: Does treatment work? In what ways does treatment alter behaviour? Does one treatment work better than another? [19]. How can we defend the argument that if people participate in any education or treatment programme that is supposed to be supportive, they estimate its effect positively? In attempts 
to respond to these questions, objective analysis seldom yields unambiguous conclusions. Programme evaluation data cannot answer questions about causal relationships between the process and the outcome of treatment. This is one of the challenges we face when we try to understand, describe and specify the effectiveness of voice therapy. The ultimate purpose of training should always be that the subjects participating in treatment programmes are satisfied with the effects obtained. However, to find out the long-term effects of a short training course, a follow-up study needs to be carried out.

\section{Conclusion}

It is commonly known that occupational voice users suffer from voice symptoms to varying extents. The goal of the 2 -day voice training programme described in this study was to give workers in call-centre customer service knowledge of how to preserve their voice. The subjects did not have any serious voice problems, although they had some vocal symptoms. The results obtained suggest that even a short vocal training course might affect positively the self-reported well-being of persons working in vocally loading occupations. Simple voice training can, in certain cases, diminish some subjective symptoms.

\section{Acknowledgements}

The authors wish to thank Ms. Arja Kotomäki, Ms. Terttu Luoma-Aho and all the participants at Sonera for their cooperation. The Finnish Institute for Speech was responsible for the voice training programme. The authors also wish to thank Ms. Hanna Oksanen (PhD) for her expert help with the statistical analyses and Ms. Sirkka-Liisa Leinonen (Lic.phil) for the linguistic revision of the manuscript. The research was supported by Sonera Corp., the Finnish Foundation of Occupational Health and Finnish Ear Research Foundation.

Appendix A. Voice symptoms experienced by females $(n=38)$ and males $(n=10)$ before the training

\begin{tabular}{|c|c|c|c|c|c|c|}
\hline \multirow[t]{2}{*}{ Question/symptom } & \multicolumn{3}{|c|}{ Females } & \multicolumn{3}{|l|}{ Males } \\
\hline & mean & SD & range & mean & SD & range \\
\hline 1 Fatigue & 2.29 & 0.73 & $1-4$ & 1.9 & 0.36 & $1-3$ \\
\hline 2 Hoarse & 2.29 & 0.75 & $1-4$ & 1.6 & 0.48 & $1-2$ \\
\hline 3 Lump & 2 & 0.58 & $1-4$ & 1.5 & 0.50 & $1-2$ \\
\hline 4 Choker & 1.34 & 0.47 & $1-3$ & 1.3 & 0.42 & $1-2$ \\
\hline 5 Mucus & 2.87 & 0.79 & $1-4$ & 2.9 & 0.90 & $2-4$ \\
\hline 6 Dry & 2.36 & 0.68 & $1-4$ & 2.4 & 0.60 & $1-3$ \\
\hline 7 Not heard & 1.53 & 0.66 & $1-4$ & 1.6 & 0.72 & $1-4$ \\
\hline 8 Worse & 2.08 & 0.65 & $1-4$ & 1.3 & 0.48 & $1-3$ \\
\hline 9 Breaks & 1.82 & 0.60 & $1-3$ & 1.6 & 0.48 & $1-2$ \\
\hline 10 No-flu lost & 1.16 & 0.27 & $1-3$ & 1 & 1 & 0 \\
\hline 11 Sick-leave & 1.24 & 0.36 & $1-2$ & 1 & 1 & 0 \\
\hline
\end{tabular}

The following scale was used (rating and qualitative description of the symptom): $1=$ 'Not even once a year/never'; 2 = 'A few times a year or sometimes'; 3 = 'Approximately once a month or quite often'; 4 = 'Almost every week/very often'. 
Appendix B. Effects of voice training in females and males

\begin{tabular}{|c|c|c|c|c|c|c|c|c|}
\hline \multirow[t]{2}{*}{ Question/symptom } & \multicolumn{4}{|c|}{ Females } & \multicolumn{4}{|c|}{ Males } \\
\hline & $\mathrm{n}$ & mean & SD & range & $\mathrm{n}$ & mean & $\mathrm{SD}$ & range \\
\hline 1 Fatigue & 28 & 1.8 & 0.96 & $0-4$ & 5 & 1 & 0 & $0-1$ \\
\hline 2 Hoarse & 23 & 2 & 1.33 & $-1-4$ & 3 & 0.5 & 0.5 & $0-1$ \\
\hline 3 Lump & 16 & 0.33 & 0.44 & $0-2$ & 3 & 1 & 0 & \\
\hline 4 Choker & 29 & 0 & 0 & $0-2$ & 6 & 0 & 0 & $-1-1$ \\
\hline 5 Mucus & 32 & 0.5 & 0.5 & $-1-3$ & 6 & 1.67 & 0.87 & $0-3$ \\
\hline 6 Dry & 23 & 2 & 2 & $-5-5$ & 5 & 1 & 0 & $0-1$ \\
\hline 7 Not heard & 14 & 0.5 & 0.5 & $0-2$ & 5 & 1 & 1 & $0-2$ \\
\hline 8 Worse & 29 & 1 & 0.5 & $0-3$ & 5 & 1.5 & 0.5 & $1-3$ \\
\hline 9 Breaks & 18 & 2 & 1.5 & $-1-5$ & 3 & 1 & 0 & $1-2$ \\
\hline 10 No-flu lost & 11 & 2.5 & 2.5 & $0-5$ & 1 & & & \\
\hline 11 Sick-leave & 9 & 0 & 0 & $-1-2$ & 0 & & & \\
\hline 12 Change & 37 & 1.8 & 1.36 & $0-5$ & 9 & 0.67 & 0.44 & $0-1$ \\
\hline
\end{tabular}

Scale of estimation from -5 to $5 ;-5$ marks a considerable change toward worse, zero marks no change and 5 marks the maximum change towards better. There is a different $\mathrm{n}$ in different questions because some employees did not experience certain symptoms before the training and it was hence not possible for them to measure how the symptoms would have changed due to the training. This table also includes question 12: 'My voice has changed due to the training'.

Appendix C. Females' $(\mathrm{n}=38)$ and males' $(\mathrm{n}=10)$ evaluation of the voice training

\begin{tabular}{|c|c|c|c|c|c|c|}
\hline & \multicolumn{3}{|c|}{ Females } & \multicolumn{3}{|l|}{ Males } \\
\hline & mean & $\mathrm{SD}$ & range & mean & $\mathrm{SD}$ & range \\
\hline 1 I can now recognise my own voice features & 3.82 & 0.44 & $2-5$ & 3.3 & 0.96 & $1-5$ \\
\hline 2 I can now recognise other people's voice features & 3.6 & 0.59 & $1-5$ & 3.3 & 0.84 & $1-4$ \\
\hline 3 My voice production has become easier after the training & 3.26 & 0.67 & $2-5$ & 2.9 & 0.54 & $2-4$ \\
\hline $\begin{array}{l}4 \text { Better understanding of voice production helps me to take } \\
\text { care of my voice }\end{array}$ & 3.84 & 0.54 & $2-5$ & 2.9 & 0.72 & $2-4$ \\
\hline 5 Voice exercises are easy to do & 3.97 & 0.51 & $2-5$ & 3.5 & 0.80 & $2-5$ \\
\hline $\begin{array}{l}6 \text { Knowledge of the factors affecting my voice helps to take } \\
\text { better care of my voice }\end{array}$ & 3.92 & 0.48 & $3-5$ & 3.2 & 0.64 & $2-4$ \\
\hline 7 Vocal practice helps me to take better care of my voice & 3.74 & 0.61 & $2-5$ & 2.9 & 0.54 & $2-4$ \\
\hline 8 Postural exercises help me to take better care of my voice & 3.84 & 0.65 & $0-5$ & 3 & 0.40 & $2-4$ \\
\hline $\begin{array}{l}9 \text { Relaxation and stretching exercises help me to take better } \\
\text { care of my voice }\end{array}$ & 3.71 & 0.65 & $0-5$ & 3.1 & 0.36 & $2-4$ \\
\hline 10 Breathing exercises help me to take better care of my voice & 3.68 & 0.70 & $2-5$ & 2.6 & 0.56 & $1-3$ \\
\hline $\begin{array}{l}11 \text { Concentration on articulation helps me to keep my voice } \\
\text { and speech clear }\end{array}$ & 3.47 & 0.79 & $1-5$ & 3.3 & 0.76 & $2-5$ \\
\hline
\end{tabular}




\begin{tabular}{|c|c|c|c|c|c|c|}
\hline & \multicolumn{3}{|c|}{ Females } & \multicolumn{3}{|l|}{ Males } \\
\hline & mean & SD & range & mean & SD & range \\
\hline 12 I learned things that I didn't know about my voice & 3.84 & 0.67 & $1-5$ & 3.5 & 0.80 & $2-5$ \\
\hline $\begin{array}{l}13 \text { I learned things that I didn't know about the use of voice in } \\
\text { general }\end{array}$ & 4.00 & 0.58 & $2-5$ & 3.7 & 0.96 & $2-5$ \\
\hline $\begin{array}{l}14 \text { While speaking, I succeed to control my breathing better } \\
\text { than before }\end{array}$ & 3.47 & 0.73 & $2-5$ & 2.8 & 0.68 & $1-4$ \\
\hline $\begin{array}{l}15 \text { While speaking, I succeed to control the ease of my voice } \\
\text { production better than before }\end{array}$ & 3.41 & 0.78 & $1-5$ & 2.8 & 0.48 & $2-4$ \\
\hline $\begin{array}{l}16 \text { While speaking, I learned to control my speaking body } \\
\text { posture and positions better than before }\end{array}$ & 4.00 & 0.37 & $2-5$ & 2.9 & 0.74 & $1-5$ \\
\hline 17 I learned new things about myself & 3.30 & 0.73 & $1-5$ & 2.7 & 0.76 & $1-4$ \\
\hline $\begin{array}{l}18 \text { I think that although I got lots of new knowledge, I still } \\
\text { cannot control my voice }\end{array}$ & 3.45 & 0.84 & $2-5$ & 3.5 & 0.70 & $2-5$ \\
\hline 19 I got useful and important knowledge concerning my work & 4.45 & 0.58 & $2-5$ & 3.6 & 0.60 & $3-5$ \\
\hline 20 I think my mood can be inferred from my voice & 3.63 & 0.72 & $2-5$ & 3 & 1.20 & $0-5$ \\
\hline $\begin{array}{l}21 \text { I can also convey the impression I want when discussing } \\
\text { in the phone }\end{array}$ & 3.55 & 0.68 & $1-5$ & 3.2 & 0.48 & $2-4$ \\
\hline $\begin{array}{l}22 \text { I can now use my voice as a tool of communication more } \\
\text { effectively than before }\end{array}$ & 3.38 & 0.65 & $2-5$ & 3.1 & 0.36 & $2-4$ \\
\hline $\begin{array}{l}23 \text { I can now react to the client's speaking pattern better than } \\
\text { before }\end{array}$ & 3.65 & 0.62 & $2-5$ & 3.5 & 0.70 & $3-5$ \\
\hline
\end{tabular}

Scale $0-5$, where $0=$ totally disagree and $5=$ totally agree; question $18: 0=$ totally agree, $5=$ totally disagree.

\section{References}

1 Titze IR, Lemke J, Montequin D: Populations in the U.S. workforce who rely on voice as a primary tool of trade: A preliminary report. J Voice 1997;11:254-259.

2 Verdolini K, Ramig LO: Review: Occupational risks for voice problems. Logoped Phoniatr Vocol 2001; 26:37-46.

3 Laukkanen AM: On Speaking Voice Exercises; diss University of Tampere, Tampere 1995. Acta Universitatis Tamperensis, ser A, vol 445 .

4 Vilkman E: Voice problems at work: A challenge for occupational safety and health arrangement. Folia Phoniatr Logop 2000;52:120-125.

Experiences of a Short Vocal Training Course
5 Pekkarinen E, Himberg L, Pentti $\mathrm{J}$ : Prevalence of vocal symptoms among teachers compared with nurses: A questionnaire study. Scand J Logop Phoniatr 1992;17: 113-117.

6 Gotaas C, Starr CG: Vocal fatigue among teachers. Folia Phoniatr 1993;45:120-129.

7 Sapir S, Keidar A, Mathers-Schmidt B: Vocal attrition in teachers: Survey findings. Eur J Disord Commun 1993;28:177-185.

8 Fritzell B: Voice disorders and occupations. Logoped Phoniatr Vocol 1996;21:7-12.
9 Smith E, Gray S, Dove H, Kirchner L, Heras H: Frequency and effects of teachers' voice problems. J Voice 1997;11:81-87.

10 Mattiske J, Oates J, Greenwood K: Vocal problems among teachers: A review of prevalence, causes, prevention and treatment. J Voice 1998;12:489-499.

11 Russell A, Oates J, Greenwood K: Prevalence of voice problems in teachers. J Voice 1998;12:467-479.

12 Smith E, Kirchner HL, Taylor M, Hoffman H, Lemke J: Voice problems among teachers: Differences by gender and teaching characteristics. J Voice 1998;12:328-334. 
13 Rantala L: Voice at Work: Female Teachers' Use and Loading of Voice (in Finnish); diss, University of Oulu, Oulu 2000. Acta Universitatis Ouluensis, Humaniora, B 37.

14 Sala E, Laine A, Simberg S, Pentti J, Suonpää J: The prevalence of voice disorders among day care center teachers compared with nurses: A questionnaire and clinical study. $\mathrm{J}$ Voice 2001;15:413-423.

15 Morton V, Watson DR: The teaching voice: Problems and perceptions. Logoped Phoniatr Vocol 1998;23:133-139.

16 Coyle SM, Weinrich BD, Stemple JC: Shifts in relative prevalence of laryngeal pathology in a treatmentseeking in population. $\mathrm{J}$ Voice 2001 ; 15:424-440.

17 Ma EP-M, Yiu EM-L: Voice activity and participation profile: Assessing the impact of voice disorders on daily activities. J Speech Lang Hear Res 2001;44:511-524.

18 Smith E, Verdolini K, Gray S, Nichols S, Lemke J, Barkmeier J, Dove $\mathrm{H}$, Hoffman $\mathrm{H}$ : Effects of voice disorders on quality of life. J Med Speech Lang Pathol 1996;4:223244.

19 Ramig LO, Verdolini K: Treatments efficacy: Voice disorders. J Speech Lang Hear Res 1998;41:S101S116.

20 Vilkman E: Occupational risk factors and voice disorders. Logoped Phoniatr Vocol 1996;21:137-141.

21 Vilkman E: A survey on the occupational safety and health arrangements for voice and speech professionals in Europe; in Dejonckere PH (ed): Occupational Voice - Care and Cure. The Hague, Kugler, 2000, pp 1-9.

22 Counsil Directive: On the introduction measures to encourage improvements in the safety and health of workers at work. 89/391/EEC. Brussels, 1989.

23 Verdolini-Marston K, Sandage M, Titze IR: Effects of hydration treatments on laryngeal nodules and polyps and related voice measures. $\mathbf{J}$ Voice 1994;8:30-47.

24 Verdolini K, Titze IR, Fenell A: Dependence of phonatory effort on hydration level. J Speech Hear Res 1994;37:1001-1007.
25 Richter B, Löhle E, Maier W, Klieman B, Verdolini K: Working conditions on stage: Climatic considerations. Logoped Phoniatr Vocol 2000;25:80-86.

26 Vintturi J, Alku P, Lauri E-R, Sala E, Sihvo M, Vilkman E: Objective analysis of vocal warm-up with special reference to ergonomic factors. $\mathrm{J}$ Voice 2001;15:36-53.

27 Lemiere C, Desjardins A, Cloutier Y, Drolet D, Perrault G, Cartier A, Malo JL: Occupational asthma due to formaldehyde resin dust with and without reaction to formaldehyde gas. Eur Resp J 1995;8:861-865.

28 Carding PN, Horsley IA: An evaluation study of voice therapy in nonorganic dysphonia. Eur J Disord Commun 1992;27:137-158.

29 Koufman JA, Blalock PD: Vocal fatigue and dysphonia in the professional voice users: Bogart-Bacall syndrome. Laryngoscope 1998;93 (suppl 5):493-498.

30 Sapir S, Atias J, Sharhar A: Symptoms of vocal attrition in women army instructors and recruits: Results from a survey. Laryngoscope 1990;100:991-994.

31 Scott S, Robinson K, Wilson JA, Mackenzie K: Patient-reported problems associated with dysphonia. Clin Otolaryngol 1997;22:37-40.

32 Linville SE: Glottal gap configurations in two age groups of women. $\mathrm{J}$ Speech Hear Res 1992;35:12091215.

33 Peppard RC, Bless DM, Milenkovic P: Comparison of young adult singers and nonsingers with vocal nodules. J Voice 1988;2:250-260.

34 Södersten M, Lindestad P- $\AA$ : Glottal closure and perceived breathiness during phonation in normally speaking subjects. J Speech Hear Res 1990;33:601-611.

35 Södersten M, Hammarberg B: Effects of voice training in normalspeaking women: Videostroboscopic, perceptual, and acoustic characteristics. Scand J Logoped Phoniatr 1993; 18:33-42.

36 World Health Organization: International Classification of Impairments, Disabilities and Handicaps. Geneva, WHO, 2001.
37 Chan RWK: Does the voice improve with vocal hygiene education? A study of some instrumental voice measures in a group of kindergarten teachers. J Voice 1994;8:279-291.

38 Carding P, Horsley I, Docherty G: A study of the effectiveness of voice therapy in the treatment of 45 patients with non-organic dysphonia. J Voice 1999;13:72-104.

39 Broaddus-Lawrence PL, Treole K, McCabe RB, Allen RL, Toppin L: The effects of preventive vocal hygiene education on the vocal hygiene habits and perceptual vocal characteristics of training singers. J Voice 2000;14:58-71.

40 Simberg S, Laine A, Sala E, Rönnemaa A-M: Prevalence of voice disorders among future teachers. J Voice 2000;14:231-235.

41 Herrington-Hall BL, Lee L, Stemple JC, Niemi KR, McHone MM: Description of laryngeal pathologies by age, sex, and occupations in a treatment-seeking sample. J Speech Hear Disord 1988;53:57-64.

42 Carding PN, Hillman R: More randomised controlled studies in speech and language therapy. BMJ 2001;323:645-646.

43 Ohlsson A-C: Voice and Work Environment: Towards an Ecology of Vocal Behaviour; diss, University of Gothenburg, Gothenburg, 1988.

44 Stemple J, Lee L, D'Amico B, Pickup B: Efficacy of vocal function exercises as a method of improving voice production. J Voice 1994;8: 271-278.

45 Carding PN, Horsley IA, Docherty GJ: The effectiveness of voice therapy for patients with non-organic dysphonia. Clin Otolaryngol 1998; 23:310-318.

46 McKenzie K, Millar A, Wilson JA, Sellars C, Deary IJ: Is voice therapy effective treatment for dysphonia? A randomised controlled trial. BMJ 2001;323:658-661.

47 Roy N, Gray SD, Simon M, Dove H, Corbin-Lewis K, Stemple JC: An evaluation of the effects of two treatment approaches for teachers with voice disorders: A prospective randomized clinical trial. J Speech Lang Hear Res 2001;44:286-296. 